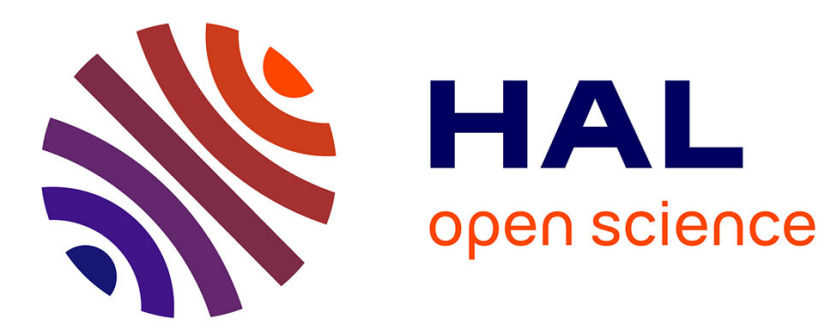

\title{
The Critical Sets of Lines for Camera Displacement Estimation: A Mixed Euclidean-Projective and Constructive Approach
}

Nassir Navab, Olivier Faugeras

\section{- To cite this version:}

Nassir Navab, Olivier Faugeras. The Critical Sets of Lines for Camera Displacement Estimation: A Mixed Euclidean-Projective and Constructive Approach. RR-2305, INRIA. 1994. inria-00074368

\section{HAL Id: inria-00074368 \\ https://hal.inria.fr/inria-00074368}

Submitted on 24 May 2006

HAL is a multi-disciplinary open access archive for the deposit and dissemination of scientific research documents, whether they are published or not. The documents may come from teaching and research institutions in France or abroad, or from public or private research centers.
L'archive ouverte pluridisciplinaire HAL, est destinée au dépôt et à la diffusion de documents scientifiques de niveau recherche, publiés ou non, émanant des établissements d'enseignement et de recherche français ou étrangers, des laboratoires publics ou privés. 


\section{The Critical Sets of Lines for Camera Displacement Estimation: A Mixed Euclidean-Projective and Constructive Approach}

Nassir Navab - Olivier D. Faugeras

$\mathbf{N}^{\circ} \mathbf{2 3 0 5}$

Juillet 1994

PROGRAMME 4

Robotique,

image

et vision

\section{apport \\ derecherche}





\title{
The Critical Sets of Lines for Camera Displacement Estimation: A Mixed Euclidean-Projective and Constructive Approach
}

\author{
Nassir Navab - Olivier D. Faugeras \\ Programme 4 - Robotique, image et vision \\ Projet Robotvis \\ Rapport de recherche $\mathrm{n}^{\circ} 2305$ - Juillet $1994-50$ pages
}

\begin{abstract}
The problem of the recovery of the motion, and the structure from motion is relevant to many computer vision applications. Many algorithms have been proposed to solve this problem. Some of these use line correspondences. For obvious practical reasons, it is important to study the limitation of such algorithms. In this paper, we are concerned with the problem of recovering the relative displacements of a camera by using line matches in three views. In particular we want to know whether there exist sets of 3D lines such that no matter how many lines we observe there will always be several solutions to the relative displacement estimation problem. Such sets of lines may be called critical in the sense that they defeat the corresponding algorithm. This question has been studied in detail in the case of point matches by early-century Austrian photogrammeters and, independently, in the mid-seventies and early-eighties by computer vision scientists. The answer lies in the idea of a critical surface.

The case of lines has been much less studied. Recently, Thomas Buchanan $[4,5]$ provided a first analysis of the problem in which he gave a positive answer: there exist critical sets of lines and they are pretty big $\left(\infty^{2}\right.$ lines). In general these sets are algorithm dependent, for example the critical set of lines for the Liu-Huang algorithm introduced in [4], but Buchanan has shown that there is a critical set that defeats any algorithm. This paper is an attempt to build on his work and extend it in several directions. First, we cast his purely projective analysis in a more euclidean framework better suited to applications and, currently, more familiar to most of the computer vision community. Second, we clearly relate his critical set to those of previously published algorithms, in particular [22,23]. Third, we provide an effective, i.e. computational, approach for describing these critical sets in terms of simple geometric properties. This has allowed us to scrutinize the structure of the critical sets which we found to be both intricate and beautiful.
\end{abstract}

Key-words: Motion from Lines, Structure from Motion, Sets of Critical Lines, Projective geometry

(Résumé : tsvp)

Unité de recherche INRIA Sophia-Antipolis

2004 route des Lucioles, BP 93, 06902 SOPHIA-ANTIPOLIS Cedex (France)

Téléphone : (33) 93657777 - Télécopie : (33) 93657765 


\section{Les droites critiques dans le problème de l'estimation du déplacement d'une caméra : une approche constructive euclidienne et projective}

Résumé : Le problème du calcul du mouvement et de la structure à partir du mouvement est important dans de nombreuses applications de la vision par ordinateur. De nombreux algorithmes ont été proposés pour résoudre ce problème. L'étude des limites de ces algorithmes est importante pour des raisons pratiques évidentes. Dans cet article nous abordons le problème du calcul du déplacement relatif d'une caméra à partir de correspondances de droites dans trois images. Nous sommes tout particulièrement concernés par la question de savoir s'il existe des ensembles de droites de l'espace tridimensionnel tels qu'il existe toujours plusieurs solutions à ce problème et ce quel que soit le nombre de droites observées. De tels ensembles de droites seront dits critiques au sens où ils vont faire échouer l'algorithme correspondant. Cette question a été étudiée en détail dans le cas de correspondances de points par les photogramètres du début du siècle et, indépendament au début des années 80 par les chercheurs en vision par ordinateur. La réponse se trouve dans l'idée de surface critique.

Le cas des droites a été beaucoup moins étudié. Récemment, Thomas Buchanan $[4,5]$ a donné une réponse positive à cette question : il existe des ensembles critiques de droites et ils sont grands (contenant $\infty^{2}$ droites). Ces ensembles dépendent en général de l'algorithme utilisé, comme par exemple l'ensemble critique de droites pour l'algorithme de Liu et Huang [4], mais Buchanan a montré qu'il existait un ensemble critique de droites qui fait échouer tous les algorithmes possibles. Dans cet article nous tentons d'étendre son travail dans un certain nombre de directions. Nous reformulons tout d'abord son analyse purement projective dans un cadre plus euclidien qui s'adapte mieux aux applications et qui est, du moins aujourd'hui, plus accessible aux chercheurs en vision par ordinateur. Nous rattachons ensuite de manière claire son ensemble critique à ceux d'algorithmes publiés, en particulier [22,23]. Enfin, nous proposons une approche effective, c'est-à-dire computationnelle, pour décrire ces ensembles critiques en terme de propriétés géométriques simples. Cette approche nous a permis d'analyser en détail la structure fine de ces ensembles critiques qui nous est apparue comme étant à la fois complexe et magnifique.

Mots-clé : Calcul du mouvement à partir de droites, calcul de la forme à partir du mouvement, ensembles de droites critiques, géométrie projective 


\section{Contents}

1 Introduction 3

2 Preliminaries 6

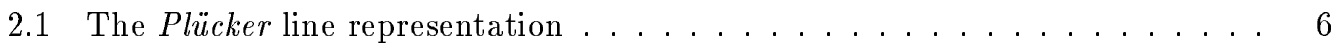

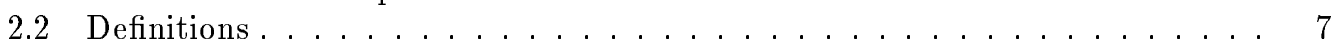

2.3 Camera displacement . . . . . . . . . . . . . . . . 8

2.4 Motion and structure from $2 \mathrm{D}$ to $2 \mathrm{D}$ line correspondences $\ldots \ldots \ldots$

3 Buchanan's characterization of the critical set of lines $\Psi \quad 10$

3.1 Definitions . . . . . . . . . . . . . . . . . . . . 10

3.2 Some properties of the critical lines . . . . . . . . . . . . . . 11

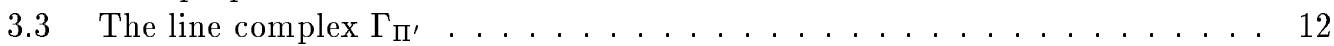

3.4 The relationship between the line complexes $\Gamma_{\Pi^{\prime}}$ and the critical sets of lines $\Psi 13$

4 A characterization of the critical sets for previously published algorithms $\mathbf{1 7}$

4.1 Some special cases . . . . . . . . . . . . . . . . . . . 18

4.1.1 1 - The plane $\Pi^{\prime}$ is the plane at infinity $\left(\Pi_{\infty}\right) \ldots \ldots \ldots 18$

4.1.2 2 - The plane $\Pi^{\prime}$ is one of the coordinate planes $\left(\Pi_{y z}, \Pi_{z x}, \Pi_{x y}\right) \ldots 19$

4.2 Complex cone . . . . . . . . . . . . . . . . . . 20

5 An alternative analysis of the line congruence $\Psi \quad \mathbf{2 2}$

5.1 Algebraic equations of the line congruence $\Psi \ldots \ldots \ldots . \ldots 22$

5.2 Order and class of the line congruence $\Psi \ldots \ldots \ldots \ldots$. . . . . . . . 24

6 Illustration of the line complex $\Gamma_{\Pi^{\prime}} \quad 28$

$\begin{array}{llr}7 & \text { Line congruence } \Psi \text { : numerical example } & \mathbf{2 8}\end{array}$

7.1 Intersection of four line complexes . . . . . . . . . . . . . 28

7.2 Direct approach . . . . . . . . . . . . . . . . . . 34

7.3 Generation and Visualization of Critical Lines . . . . . . . . . . . . 35

8 Conclusion $\quad 46$

A Algebraic characterization of $\Theta$ 's order and class 46 


\section{List of Figures}

1 In this figure $\mathbf{m}_{1}$ and $\mathbf{m}_{1}^{\prime}$ have the same image coordinates. Therefore for the same image point pair correspondences $\mathbf{m}$ and $\mathbf{m}_{1}$ there exist at least two solutions $(\mathbf{R}, \mathbf{T}, \mathbf{M})$ and $\left(\mathbf{R}^{\prime}, \mathbf{T}^{\prime}, \mathbf{M}^{\prime}\right)$ for the structure from motion problem

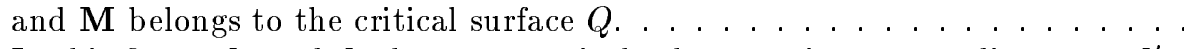

2 In this figure $\mathbf{d}_{1}$ and $\mathbf{d}_{\mathbf{2}}$ have respectively the same image coordinates as $\mathbf{d}_{1}^{\prime}$ and $\mathbf{d}_{\mathbf{2}}{ }^{\prime}$. Therefore for the same triplet of image lines correspondences $\mathbf{d}, \mathbf{d}_{1}$ and $\mathbf{d}_{2}$ there exist at least two solutions $\left(\mathbf{R}_{1}, \mathbf{T}_{1}, \mathbf{R}_{2}, \mathbf{T}_{2}, \mathbf{D}\right)$ and $\left(\mathbf{R}_{1}^{\prime}, \mathbf{T}_{1}^{\prime}, \mathbf{R}_{2}^{\prime}, \mathbf{T}_{2}^{\prime}, \mathbf{D}^{\prime}\right)$ for the structure from motion problem and $\mathbf{D}$ belongs to the critical set of lines $\Psi . \ldots \ldots . . \ldots . \ldots 5$

3 The vectors $\mathbf{n}$ and $\mathbf{l}($ see text). . . . . . . . . . . . . . . 6

4 The relationship between $\Psi$ and $\Psi^{\prime}$. . . . . . . . . . . . . . . . . . 11

5 Used in the proof of proposition 3. . . . . . . . . . . . . . . . . . . 14

6 Used in the proof of proposition 4. . . . . . . . . . . . . . . . 15

7 Used in the proofs of propositions 4 and 5 ............... . . 16

8 Illustration of the line complexes $\Gamma_{\Pi_{\infty}^{\prime}}, \Gamma_{\Pi_{y z}^{\prime}}, \Gamma_{\Pi_{z x}^{\prime}}$, and $\Gamma_{\Pi_{x y}^{\prime}}, \ldots \ldots 29$

9 Intersections of the four complex cones and the trifocal plane. . . . . . . . . 31

10 Intersections of the four complex cones and the three-focal-pane. . . . . . . . 32

11 Illustration of the line complex $\Gamma_{\Pi_{g}^{\prime}} \ldots \ldots . \ldots . \ldots . \ldots . . \ldots 33$

12 Images of $S$ and $S^{\prime}$ in two triplets of cameras. . . . . . . . . . . . . 36

13 Cross-Fusion stereogram of $S$, a subset of $\Psi$ corresponding to $S^{\prime}$ (figure 14 ). 37

14 Cross-Fusion stereogram of $S^{\prime}$, a subset of $\Psi^{\prime}$ corresponding to $S$ (figure 13 ). 38

15 Cross-Fusion stereogram of a subset of critical lines $\Psi$. The left image is from the point of view of $C_{0} \ldots \ldots \ldots$. . . . . . . . . . . . . . . . . 39

16 Cross-Fusion stereogram of a subset of critical lines $\Psi^{\prime}$ corresponding to subset of $\Psi$ presented in figures 15,17 , and 19 . The left image is from the point of view of $C_{0}^{\prime}$. . . . . . . . . . . . . . . . . . . . . . . 40

17 Cross-Fusion stereogram of a subset of critical lines $\Psi$. The left image is from the point of view of $C_{1} \ldots \ldots \ldots \ldots 1$

18 Cross-Fusion stereogram of a subset of critical lines $\Psi^{\prime}$ corresponding to subset of $\Psi$ in figures 15,17 , and 19 . The left image is from the point of view of $C_{1}^{\prime} .42$

19 Cross-Fusion stereogram of a subset of critical lines $\Psi$. The left image is from the point of view of $C_{2}$. . . . . . . . . . . . . . . . . . 43

20 Cross-Fusion stereogram of a subset of critical lines $\Psi^{\prime}$ corresponding to subset of $\Psi$ in figures 15,17 , and 19 . The left image is from the point of view of $C_{2}^{\prime} .44$

21 Cross-Fusion stereogram of 10 lines, 5 lines of $\Psi$ and their corresponding 5 lines from $\Psi^{\prime}$. The left image is from the point of view of the first camera $C_{0} . \quad 45$ 


\section{Introduction}

The estimation of 3D motion and structure from sequences of images is well-known to be a difficult one because of its instability but one whose solution has great potentials for many applications. One possible line of attack for this problem is to identify features in the sequence of images that is being analyzed, make sure that they belong to the same rigidly moving object in the scene, and track them over time. This tracking can be used directly to establish useful constraints on the kinematic screw of the moving object and, sometimes, to actually compute it. This might be called the instantaneous approach and the literature on the subject is gigantic $[18,14,2,46,41,9]$. The tracking can also be used to establish correspondences between images of the scene taken at different time instants. These correspondences can then be used to estimate the displacement of the moving object or of the camera. This might be called the discrete approach. When the time interval between the images becomes smaller, the two approaches coincide. In this paper we discuss only the discrete case.

The case of point features has been studied in detail. The problem is as follows: given $n$ point correspondences in two images, assumed to be on the same static object, is it possible to recover the camera displacement. We have been able to trace this problem back to Chasles [6] and it has received a great deal of attention both in photogrammetry $[13,51,3,1,7,35$, $36,49,48]$ and in computer vision $[24,43,8]$. Some of this work has shown that there were cases where several solutions could be obtained and the next natural question is when is the solution unique, i.e. when is it possible to recover unambiguously the camera displacement. In fact it is the reverse question that has received the most attention: does there exist sets of points for which no matter how many points we measure from that set we will always find several solutions to the camera displacement. This question has been answered positively by the same two communities. The photogrammeters have discovered that if the points lay on "gefährliche Flächen" then there were always at least two solutions $[19,50,15]$. This has been rediscovered by computer vision scientists later $[25,16,28,26,34,29,17,30]$, and the "gefährliche Flächen" renamed critical surfaces (see Figure 1).

The case of line features has not received much attention to our knowledge from the photogrammetry community and some attention from the computer vision community $[4,5$, $33,32,31]$. The problem is as follows: given $p$ triples of line correspondences in three images, assumed to be on the same static object, is it possible to recover the camera displacements. Three views are required because two views of straight lines do not impose any constraints upon the camera displacements. Most of the work has been to write down the constraints that come out of the observation of one line in three views and to propose algorithms for solving efficiently the system of nonlinear equations resulting from the observation of $p$ such lines $[21,10,22,23,20,39,45,47]$. The question of the critical sets of lines has only been brought up recently by Thomas Buchanan $[4,5]$. The problem can be phrased in a way that is similar to that of points: for a given algorithm, does there exist sets of lines such that, no matter how many lines we observe in these sets, we will always find several solutions for the camera displacements. The reason why this is important should be clear now: having recovered the displacements it is then possible to reconstruct the $3 D$ lines. 